\title{
UNA PRESENTACIÓN DE LA HISTORIA DE ROMA A TRAVÉS DE LOS HISTORIADORES MENORES, BIÓGRAFOS Y PANEGIRISTAS DEL SIGLO I
}

M.a José López de Ayala y Genovés

$U N E D$

Como preámbulo a la exposición de nuestro tema, en breves líneas, analizaremos el problema que sigue planteando la necesidad de agrupar los hechos literarios según su orden lógico y real. Este punto, como dice SchanzHosius y comenta en su artículo González Rolán ${ }^{1}$ presenta en Roma su auge al comprobar que "cada autor, con excepción de los cómicos practicaban más de un género literario; que casi todos los géneros literarios se cultivaban en un mismo período y, finalmente, que el historiador tiene que habérselas con una serie de problemas de sistematización.»

Nuestro trabajo responde - en cierta manera - a una sistematización por medio de los géneros literarios recogiendo, como dicen Wellek y Warren ${ }^{2}$ : «el esquema de referencia, el eslabón de unión y la continuidad entre tradiciones y épocas aparentemente dispares». Teniendo en cuenta esto último también nuestro trabajo está marcado por el procedimiento de la segmentación por periodos, aunque no sometido a ellos totalmente, sólo en tanto en cuanto recogemos una época determinada del desarrollo de la historiografia en Roma, es decir, la relativa al primer siglo de nuestra era, final de Principado de Augusto y comienzos de la dinastía Antonina. De esta manera según Wellek y Warren ${ }^{3}$, «El problema de escribir la historia de un período será primero un problema de descripción: es menester discernir la decadencia de una convención y la aparición de otra».

1 T. González RolÁn, «Ordenamiento de la historia de la literatura». IV Congreso Español de Estudios Clásicos, Madrid 1973, pág. 242.

2 R. Wellek, A. Warren, Teoria literaria. trad., Madrid 1969, págs. 313-314.

${ }^{3}$ Ibidem, pág. 320. 
La historia del siglo primero tiene unas características muy diversas e interesantes. Es la época de una historia moralizante, retórica y novelesca a la que le estaba vedada la total independencia. La producción literaria crece cuantitativamente; se crea un equilibrio entre los refinamientos de los círculos aristocráticos y los gustos literarios del gobierno. La oleada de orientalismo helenizante queda neutralizada, en parte, por la aportación de las provincias occidentales en que la lengua latina, fijada por las normas clásicas, domina poderosamente. Sin duda, estas provincias enriquecen también el cosmopolitismo romano con sus caracteres nacionales; por último, la capacidad técnica, aún en los literatos mediocres, es considerable. La fuerza de la retórica se robustece cada vez más y la historiografia romana llega a su cima más alta en la figura de Tácito. Se cultiva especialmente la filosofia, considerada como un fuerte elemento liberador; el estoicismo tiene gran importancia. El propio Oriente empieza a determinar el pensamiento latino con sus cultos. Los dioses de Asia Menor y de Egipto triunfan con Claudio y Calígula; el judaísmo seduce los espíritus y el cristianismo, perseguido por Nerón, comienza a tener adeptos ${ }^{4}$.

La literatura de esta época se presenta de una forma compleja y contradictoria que contrasta con el plan armónico de la época precedente. Fue necesario que surgieran hombres dotados de una gran originalidad para poder renovar la literatura latina sin romper con el pasados.

\section{1. Época Julio-Claudia ${ }^{6}$}

Del 14 al 68 d. C. se suceden en Roma cuatro emperadores descendientes todos de Tiberio Claudio Nerón. Todos ellos de nefasta reputación, déspotas y crueles, que consiguieron la destrucción de las grandes familias aristocráticas. Los talentos intelectuales y artísticos de los emperadores hacían esperar que darian a la literatura la protección que había gozado con $\mathrm{Au}-$ gusto, pero su gran despotismo no favorecería la literatura nacional y romana.

Los escritores o adulaban el poder o eran víctimas. Origina esto el gran individualismo de los autores de este tiempo, con tendencia a expresar un pensamiento universal.

4 J. BAyET, Literatura Latina, Barcelona 197233, pp. 326-331

${ }^{3} \mathrm{H}$. BARDON, La littérature latine inconnue, II, Paris 1956.

'J. WiLkES, «ulio-Claudian Historians», $C W, 65,1972$, pp. 179-183. 
La sociedad no es la misma que la del tiempo de Augusto, existen elementos políticos y étnicos nuevos y se han realizado transformaciones morales profundas.

Los escritores no son propiamente romanos, vienen de las partes más lejanas del Imperio. La literatura sufre una doble influencia: griega y oriental por una parte, gala e hispana por otra. El sistema de educación y la lengua imponen una cierta mentalidad común a espíritus tan diversos, pero ellos introducen imágenes de pensamiento y sentir nuevos. La generación literaria del 14 al 68 manifiesta un gusto por el preciosismo y el énfasis debido a la influencia de los escritores hispanos. La historiografia de estos años ha descendido del rango donde la habían colocado César, Salustio y Livio, ya que del 10 a. C. al $40 \mathrm{~d}$. C. es una época militarmente estática, que abarca sólo la expedición a Germania de Varo, Druso y Germánico?

El período Julio-Claudio supone un gran incremento de la autoridad imperial y una degeneración hacia el despotismo oriental. Este status político supondrá una regresión en la línea de los grandes historiadores, cultivándose tan sólo los géneros menores: biografias y crónicas.

La divulgación del género historiográfico, tratado por casi todos los oradores, tiene escasas muestras de calidad e independencia de pensamiento. Este retroceso se debe en parte a la regresión de los cronistas no favorables al Principado y a una auténtica crisis de talentos en el panorama de las letras. Es una época caracterizada por el desequilibrio y la intranquilidad, con una cultura determinada por la retórica, la elocuencia, y por la búsqueda de la palabra arcana y pulida, en la que puede hablarse de «descientificación» de algunas disciplinas e incluso llega a constatarse la gran preocupación del escritor por el destino del emperador ${ }^{8}$.

Gracias a los testimonios históricos conocemos que Tiberio y Calígula ${ }^{9}$ no sólo están relacionados por la desaparición de sus obras, sino por una tendencia común a reaccionar contra la actitud literaria de Augusto; éste ${ }^{10}$ recomienda la precisión y claridad de la lengua y el arcaísmo le desagrada; todo lo contrario de Tiberio que fue un arcaico, amaba lo complicado y oscuro, como bien señala Tácito ${ }^{11}$. Su antagonismo, no obstante, no impide una comunicación epistolar cordial, como deja señalado Suetonio. De Tiberio sólo conservamos una Autobiografia carente de pretensiones literarias y editada al final de su reinado.

7. BARDON, La littérature..., III, op. cit., pp. 123 ss.

"A. H. McDonalD, "Theme and Style in Roman Historiography", JRST, 65, 1975, pp. $1-10$.

H. BARDON, Les empereurs et les lettres latines d'Auguste a Hadrien, Paris 1940. pp. 146-160.

${ }^{10}$ Svet. Calig. 53.

$"$ TÁC. Dial. 18 y Ann. 13,3. 
Por el contrario, Claudio ${ }^{12}$ fue un hombre de ciencia, erudito y meticuloso, nació en Lyon en el 41 a. C. Con él, el griego llega a ser lengua oficial en el imperio, y no titubea en emplearla en el Senado. La novedad es muy importante. Claudio es un historiador y un gramático. Escribe en griego una Historia de los Tirrenos y una Historia de Cartago; en latín una Historia de Roma (desde Julio César, año 27 a. C. al 14 d. C., aunque otros creen que llega al 41 d. C.) y por último una Autobiografia. El valor de las obras de Claudio no radica exclusivamente en el equilibrio entre el latín y el griego, sino especialmente en que son una continuación del esfuerzo comenzado por Livio $^{13}$. Plinio ${ }^{14}$ pone en duda las fuentes de su documentación por la frecuencia y gravedad de sus errores históricos.

Claudio defiende a Cicerón de los ataques de Asinio Galo, hijo de Asinio Polión, muerto en el $33 \mathrm{~d}$. C. ${ }^{15}$.

A pesar de la influencia de Livio, la prosa de Claudio es original, unión compleja de defectos y de cualidades; difiere de la de Augusto en la concepción de la cultura más acorde con el criterio de Tiberio.

En el marco de estos emperadores nace una nueva situación de la literatura marcada por la inseguridad y la persecución de los escritores bajo pretexto de la Lex maiestatis, vieja ley republicana en donde el régimen nuevo conserva la letra sin respetar el espíritu ${ }^{16}$.

En el 25 d. C. todavía tiene lugar el proceso de Cremucio Cordo ${ }^{17}$, que, en la época de Augusto, había tratado en sus obras de los comienzos del régimen imperial. Siguió la moda favorable a las Historiae, a pesar de haber llamado Tácito a su obra Annales, es decir, escribir dentro de la ideología republicana atacando algunos aspectos del principado. Fue objeto de una fuerte persecución por los partidarios de Sejano en el 21, al considerarlo admirador de Bruto y Casio, que acabó con su condena a muerte y la prohibición de sus obras hasta que Caligula ${ }^{18}$ las rehabilitó. Sus ideas conectan con el estoicismo, lo que valió tener a Séneca el Viejo como defensor ${ }^{19}$. Fue un historiador adverso a Tiberio $^{20}$.

En el 34 (época de Tiberio) Mamerco Emilio Escauro, orador, es acusado de escribir una Tragedia atacando a Tiberio ${ }^{21}$, a quien se le atribuyen algunos Libelli.

${ }^{12}$ H. BARDON, Les empereurs..., op. cit., p. 123.

${ }^{13}$ A. Momigliano, L'opera dell' imperatore Claudio, Florencia 1932. 391.

14 F. MUnZER, Beitrag zur Quellenkritik der Naturgeschichte des Plinius, Berlin 1897, p.

is Svet, Claud. 41.

16. M. BARDON, Les empereurs..., op. cit., p. 165.

17 TÁC. Ann. 4. 34.

18 Quint. Inst. 10, 1, 104.

19 SEN. Dial. 6, 22, 4.

20 SÉN. Dial. 6, $22,4$.

${ }^{21}$ TÁC. Ann. 6, 29; 3, 66. 
Tiberio y Claudio completan la obra de Augusto pero con una línea de actuación algo diferente. El esfuerzo de Augusto por elevar la condición del hombre de letras con el acercamiento al emperador está muy claro; por el contrario, estos emperadores no buscan la amistad con los escritores. $Y$ esto se explica por la consolidación de la monarquía, la ausencia de grandes talentos, el deseo de los emperadores de someter a los escritores, el temperamento personal de cada uno de ellos y sobre todo, el gran interés de romper con la actitud augustea ${ }^{22}$.

Partidario de Tiberio, con quien luchó en Germania, fue Veleyo Patérculo $^{23}$ quien redactó con agrado las etapas de su carrera política que debía en su totalidad al emperador. Su obra, apología continua del Imperio, de los emperadores y de Tiberio, muestra a Veleyo como un agente político. Su Historia Romana está dedicada a Vinicio, cónsul del año 30 y describe, en dos libros, toda la historia del mundo grecorromano desde la Guerra de Troya. Su obra, que quiere ser analítica, no es más que un monumento elevado a la memoria de tres césares: César, Augusto y Tiberio, en lo que refleja su influencia de Salustio y su alejamiento de Livio. Tiberio será el personaje central de su obra en quien convergen todas las líneas de fuerza, aunque no pasa por alto el sentido político del Principado. El régimen creado por Augusto y seguido por Tiberio tiene una misión reparadora, es decir, la paz exterior y la paz civil. En resumen, restaurar la tradición republicana; por ello Tiberio salva a la vez el Imperio y la República.

En un momento en que los historiadores antirromanos difunden la idea de fragilidad del Imperio, Veleyo celebra la potencia ecuménica de Roma «difundida sobre la extensión de Oriente y Occidente, desde los límites del mediodía a los del septentrión». La pax augusta abolió el temor al bandidaje en todos los rincones del universo ${ }^{24}$.

A pesar de todo, su obra es un resumen muy desigual y desconcertante. Se preocupa de la precisión cronológica, gusta de las visiones de conjunto de los grandes problemas; la obra no es equilibrada pues el efecto retórico que persigue es desmesurado y da una sensación artificial. Si Veleyo carece de independencia al narrar la historia antigua, resulta valioso como historiador contemporáneo en los primeros tiempos del Principado. La narración de lo vivido resulta viva e interesante. Sirve también Veleyo para contrarrestar a los historiadores antiguos como Timágenes y Trogo Pompeyo, que muestran el Imperio como una potencia universal. Toda su obra está marcada por una filosofia de fondo. En el estudio sobre la causalidad del

${ }^{22}$ H. Bardon, Les empereurs..., op. cit., pp. 168-172.

${ }^{23}$ R. J. GoAR, «Horace, Velleius Paterculus and Tiberius Caesar», Latomus, 35, 1976, pp. 43-54.

${ }^{24}$ J. Hellegouarc'H et Cl. Jodry, «Les res Gestae d'Auguste et l'Historia Romana de Velleius Paterculus", Latomus, 39, 1980, 803-816. 
devenir histórico desecha la intervención de la cólera divina en las batallas y explica el éxito de los personajes por su acción y su valía. Cree en un determinismo colectivo que descarta la posibilidad de que los gobernantes controlen la totalidad del devenir histórico ${ }^{25}$.

Contrasta la visión de Tiberio of recida por Veleyo con la que, más tarde nos ofrecerá Tácito, analizador de los errores políticos de la dinastía JulioClaudia y de la ruptura del equilibrio político instaurado por Augusto.

Woodman, en su prólogo a la edición de los 38 capítulos de esta obra ${ }^{26}$ intenta decidir si Veleyo hace historia, biografia o panegírico. Pero se niega a tomar partido por uno de estos géneros demostrando que en Roma, al final de la República y comienzo del Imperio, el carácter biográfico es algo inherente a la historia, incluso entre Tito Livio y Tácito. Y Veyelo Patérculo formaría parte de la tradición historiográfica latina. Por otra parte, justifica el tratamiento laudatorio que recibe la figura de Tiberio como una consecuencia del marcado carácter de exaltación patriótica que tiene la historiografia romana en todas las épocas. Y de esta forma la historia en forma de biografia toma fácilmente el aspecto de un panegírico.

Lo que parece indiscutible, según recoge Woodman ${ }^{27}$, es que Veleyo hace ese tipo de historia laudatoria condenada por Tácito, que ignora a este autor, así como es ignorado por el resto de las autoridades de la Antigüedad. Desde luego, su admiración por Tiberio y por la casa imperial no tiene límites, los ministros del emperador -incluido Sejano- no pueden equivocarse, según Veleyo.

En cuanto a su valoración histórica hay que decir que nos hallamos ante un historiador más entusiasta que crítico. Su interés se centra en los individuos, y retrata hábilmente los aspectos secundarios de la historia, así como sus protagonistas.

Su estilo es un ejemplo de la prosa post-augustea, y un anuncio de lo que será la prosa posterior, con múltiples concesiones a la retórica. Son torpes sus intentos de utilizar un estilo conciso de oraciones breves. Se complace, sin embargo, en el uso de las frases largas, formadas generalmente a base de yuxtaposiciones intercaladas por paréntesis. También abusa de las interrogaciones y exclamaciones. Su narrativa, a veces, capta al lector pero tiene muy poca profundidad, debido quizá a cierto apresuramiento al escribir esta obra, hecho que el mismo Veleyo reconoce.

Otro representante de la historiografia retórica, moralizante y novelesca

${ }^{25}$ R. J. StarR, «Velleius literary techniques in the organization of his history», TAPhA 110,1980 , pp. 287-301.

${ }^{26}$ A. J. Woodman, "Velleius Paterculus", The Tiberian narrative $(2,94,131)$, Cambridge 1977, resumen en Latomus, 1980, pp. 198-199.

${ }^{27}$ A. J. WOODMAN, "Questions of date, genre, and style in Velleius: some literary answers", CQ 25, 1975, pp. 282-286. 
y al que Ramelli ${ }^{28}$ dedica un estudio muy interesante y exhaustivo lo tenemos en Valerio Máximo, amigo de Sexto Pompeyo (13 d. C.) y hombre de letras. Una invocación a Livio y un discurso contra Sejano, datan la composición de su obra alrededor del 29-32 d. C. Es un constante adulador de Tiberio, que se interesa por la anécdota como ejemplo de la personalidad de la figura que trata. Tiende a ver en la historiografia romana una logomaquia entre las virtudes o los valores del pueblo y las seducciones decadentes de lo extranjero. Su obra Facta et dicta memorabilia es útil como una enumeración de hechos a veces callados por otros autores, pero carentes de valor científico. Se presenta como un autor reaccionario y odioso contra los gracos ${ }^{29}$ y los republicanos Casio y Bruto.

El tono de adulación es totalmente diferente al utilizado por Veleyo; admira al emperador como garantizante de las leyes y de la paz y destaca la supremacía de la disciplina militaris. Su obra encierra un sentimiento hostil contra la plebe.

A pesar de su admiración por Cicerón, abusa de la antítesis y no le importa cambiar el orden de las palabras si con ello puede conseguir un mejor efecto de estilo y de ritmo. Su fuente de información procede de una recogida directa en los grandes escritores griegos y latinos; este material, ordenado y elaborado, lo ofrece a sus contemporáneos y sobre todo a la escuela retórica. La obra sustituye y supera una recopilación ya existente de época augustea, no sólo en su esquema de composición, sino también en la independencia acerca de las fuentes que maneja, por lo que se deduce que la obra de Valerio Máximo estaba más al día y era más accesible.

No se puede negar que las fuentes para este escritor son Cicerón y Livio y también Varrón, Nepote, Hygino, Celio, Antípater y Pompeyo Trogo. Puede precisarse mejor el nivel de información adquirido a través de Cicerón pero resulta más complicado cuando se trata de Livio, historiador casi contemporáneo, esto se debe a la pérdida de una gran parte de la obra de Valerio. De la que nos ha llegado, podemos deducir que ha hecho gran uso del historiador Patavino. Él, más tarde, lo será para Plinio y Verrio Flaco. La diferencia entre Valerio y Plinio, reside en que el primero no aporta modificaciones sustanciales al texto que transcribe, mientras que Plinio acostumbra a modificar la disposición de los exempla según su orden más lógico.

En el $62^{\circ}$ d. C. muere Aufidio Baso ${ }^{30}$, contemporáneo de Séneca el filósofo, a quien se le atribuyen dos obras: Libri belli germanici ${ }^{31}$ (es una

${ }^{2 k}$ A. Ramellu, "Le fonti di Valerio Massimo», Athenaeum 14, 1936, pp. 117-152.

${ }^{24}$ VAL. MaX. 3, 2, 17; 6, 8, 4; $1,5,7$ y $6,17$.

"Cf. para este historiador lo expresado por J. Wilkes en su articulo ya citado. pp. 192-197.

"Cf. QVINT. Inst.10, 1, 103. 
exaltación de Tiberio) y unas Historiae romanas de las guerras civiles hasta Claudio (40-41), que más tarde fue continuada por Plinio el Viejo en su $A$ fine Aufidii Basii. Sus obras son importantes y muy cualificadas por Tácito ${ }^{32}$, quien las utiliza como fuente de información en su Germania.

Sobre este autor entran en juego dos preguntas: 1. ieran una o dos las obras? 2. ¿estaba a favor o en contra del emperador? Cuestiones bastante discutidas. Para Dión, Aufidio Baso es opuesto al régimen y son dos sus obras, no asi para Tácito ${ }^{33}$.

Asociado, según fuentes de Tácito y Quintiliano ${ }^{34}$, a este autor está Servilio Noniano ${ }^{35}$, cónsul en el 35 y muerto en el 59 , después de haber sido uno de los personajes más importantes de su época. Su amistad con Persio lo sitúa dentro de la oposición senatorial. Él fue a la vez orador e historiador y resulta muy dificil discernir cuál es el sujeto de su historia. Por su 1 ango los niveles de información son muy buenos y centrados en su tiempo, es decir, en la época de Claudio.

Con la historia despojada de libertad, los nuevos maestros que surgen son vulgares y esta situación no cambia con Calígula como hemos podido conocer a traves de Léntulo Getúlico, legado en la Germania Superior entre los años 29-39 y autor de una obra histórica de la que tenemos noticias por Suetonio ${ }^{36}$.

Caligula $^{37}$ interviene más que Tiberio en la literatura. Es hostil al estilo de Séneca el Viejo ${ }^{38}$, odia a los escritores alabados por Augusto y muestra aversión por Livio ${ }^{39}$. Para oponerse a Augusto y Tiberio rehabilita las obras de Casio Severo y Cremucio Cordo. Nerón rompe en favor del griego el equilibrio sostenido por Claudio. Su originalidad viene marcada por su gusto poético con matices dramáticos y épicos. Proyectó escribir una epopeya sobre la Historia de Roma que no llevó a cabo. La condena y la muerte de Séneca seguida de la de Lucano y su intolerancia a la idea republicana indican claramente el retorno a la censura más rigurosa. Los escritores políticos desaparecieron totalmente en esa atmósfera, pero la ciencia siguió cultivándose con cierta brillantez, aunque, al suprimir la libertad de pensamiento Roma había empezado a renunciar también a ser la capital intelectual del Imperio.

En esta época gustan de escribir sus memorias: Agripina (de quien hacen

32 TÁc. Dial. 23.

${ }^{33}$ Para este punto cf. H. BARDON, La littérature... op. cit., pp. 164-166.

34 QVINT. Inst., 10, 1, 103. 197-199.

${ }^{35} \mathrm{Cf}$. además para este historiador lo expresado por J. Wilkes es un artículo ya citado pp.

${ }^{36}$ SVET. Cal. 8.

${ }^{37}$ H. BARDON, Les empereurs..., op. cit., pp. 178-182.

38 DiON 59, 19.

39 Svet. Cal. 34. 
mención Tácito ${ }^{40}$ y Plinio el Viejo), Domicio Córbulo y Antistio Veto, cónsul en el 55, que relató sus hazañas en Germania y que es consultado por Plinio el Joven al escribir su Naturalis Historia ${ }^{41}$.

De Domicio Córbulo, muerto en el 67, no conocemos el título de su obra. Por su situación política pudo obtener gran información que favoreció la importancia de su obra posteriormente utilizada por Tácito ${ }^{42}$. Dión Casio y Plinio el Viejo ${ }^{43}$.

Para terminar citaremos a Suetonio Paulino que comienza a escribir sus memorias en tiempo de Nerón. Narra su participación en las campañas de Mauritania (42), de Britania (59-61) y su enfrentamiento con Vitelio estando en el ejército de Otón. Carecemos de información directa y sólo llega hasta nosotros a través de Plinio ${ }^{44}$ y por la utilización que de Córbulo y Suetonio Paulino hace Quinto Curcio.

La historiografía en tiempos de Nerón ${ }^{45}$ viene marcada por la parcialidad como lo refleja la obra de Cluvio Rufo ${ }^{46}$ (cónsul en el $41 \mathrm{~d}$. C.) que participa de la época de Nerón y de la crisis de los años 68 y 69, tomando primero partido por Otón y más tarde por Vitelio. Narra la muerte de Calígula, la elevación de Claudio y las amenazas de Agripina; su obra llega hasta el año 69, fecha de la muerte de Vitelio. Este historiador es fuente principal para Tácito en la segunda parte de sus Annales y para Suetonio cuando escribe de Claudio y Nerón ${ }^{47}$. Más tarde puede verse también su influencia en la obra de Flavio Josefo.

Los biógrafos, durante esta época, tienen también sus representantes. Así, Séneca con una Vita acerca de su padre; Plinio el Viejo ${ }^{48}$ y la obra Vida de Pomponio Segundo; Julio Segundo ${ }^{49}$ y la biografia de su contemporáneo Julio Africano. Pero sobre todo Asconio Pedanio ${ }^{50}$, gramático del 9-76 d. C., conocido admirador de Salustio, como se refleja en su Vida de Salustio; son interesantes también las ilustraciones históricas de las Orationes de Cicerón ${ }^{51}$.

Los biógrafos más alabados de este tiempo fueron Peto Trásea y Anteyo,

4 TÁC. Ann. 15, 16.

"Cf. M. Schanz, C. Hosius, G. Kruger, Geschichte der röminschen Literatur, II 2, Munich 1966, p. 345.

${ }^{42}$ TAC. Ann. 11, 18-20; 12, 27-28.

${ }^{43}$ Plin. Nat. 2, 180; 5, 83; 6, 23 y 6,40 .

4 Plin, Nat. 5, 14.

4 H. BARDON, La littérature..., op. cit., pp. 193 ss. y 214 ss.

46. para este autor lo expresado por J. Wilkes en su articulo ya citado, pp. 202-203; y Th. Mommsen «Cornelius Tacitus und Cluvius Rufus», Ges. Schr. 7, p. 224.

${ }^{47}$ Svet. Nero 21, 2.

47. Plin. Ep. 3, 5, 8, cf. PLIN. Nat. 14, 56.

4 TÁC. Dial. 14.

so [ACR.] 1, 2, 4.

sI M. Schanz, C. Hosius, G. KRuger, op. cit., II, p. 731. 
los dos en gran oposición a Nerón. Trásea, amigo de Persio, consagra a Catón de Útica ${ }^{52}$ un escrito bajo la forma de biografia. Anteyo escribe una Vida de su amigo Ostorio Escápula. Su existencia está atestiguada por Tácito, Suetonio y Dión Casio ${ }^{53}$.

\section{2. ÉPOCA FlAViA $(69-96)^{54}$}

Muerto Nerón y superada la crisis de los años 68-69, los tres emperadores de la época Flavia se mueven en unas circunstancias políticas muy dificiles: persecuciones internas, caótica situación económica, revueltas externas, etc. Con esta situación el retorno en los escritos de la época al pasado es más una afirmación que una realidad y una sugestión para defenderse del peligro de las tiranias greco-asiáticas. La oratoria no es libre; con la presencia de los delatores, desaparece la inspiración y lo laudatorio desemboca en panegírico. La filosofia decae y, en su lugar, surge la sátira. El nacionalismo de autores como Tácito, Plinio el Viejo o Juvenal es, por otra parte, mezquino e inactual. Su aversión a Grecia y a Oriente revela el miedo a un cosmopolitismo que ofrecía sin duda el inconveniente de las disgregaciones, al que Roma debía resignarse, si no quería perder su poder.

Vespasiano, proclamado emperador en julio del 69, es autor de unos Comentarios, que fueron publicados en el 94 y conocidos a través de Flavio Josefo $^{55}$. Utiliza la historia para fines políticos e intenta establecer el principio de sucesión en su propia familia por orden de primogenitura. Fue menos generoso con los escritores y ejerció sobre la historia una gran influencia por su manera de ser y por las necesidades de su situación política. Imita a Augusto, pero maniobra con menos habilidad. A pesar de todo, consigue que los escritores de su época sean adictos a su dinastía ${ }^{56}$.

Seguidor de Vespasiano es Fabio Rústico, que puede ser situado entre el 79 y el 108, esto se deduce de la documentación que utiliza para su obra en la que nos habla de Claudio, de Nerón y de su adhesión a Séneca. Tácito nos habla de él en su Agricola $^{57}$ y Plutarco lo utilizará en sus biografías sobre Galba y Otón ${ }^{58}$.

52 Puvt. Cat. Min. 37.

${ }^{33}$ Cf. para esta afirmación lo recogido por H. BARdon, La littérature..., op. cit., p. 170.

\$4 H. BARDON, La littérature..., op. cit., pp. 177 ss.

ss Ios. Bell. Iud. 4, 1, 39 ss.; cf. Ap. 1, 10; Vit. 65 y H. PeTER, HRF I, p. 143.

${ }^{56}$ H. BARDON, Le empereurs..., op. cit., pp. 266-268.

57 TÁC. Agr. 10.

${ }^{88}$ Cf. J. WILKES, op. cit., p. 201 nota 68. 
Tambiẻn de esta época, y a través de Tácito $^{59}$ que los considera fuente de sus Annales, conocemos a Pompeyo Planta ${ }^{60}$, prefecto de Egipto en el 97, que escribió sobre los desórdenes del año 69.

Plinio el Viejo (23-79) ${ }^{61}$ nació en Como y su vida se desarrolla entre el final de la dinastía Julio-Claudia y el comienzo de la dinastía Flavia. Educado en Roma, muy pronto comenzó su carrera militar que motivó su obra Sobre el empleo de la jabalina en la caballería. Participó en la guerra de Germania y su admiración por Pomponio Segundo ${ }^{62}$ dio lugar a su biografia. Vuelve a Roma en el 57 ó 58, dedicándose a escribir tratador retóricos y gramáticos, como el Dubii sermonis libri octo y su Studiosi libri tres, dedicado a su sobrino Plinio el Joven.

Con la llegada al poder de Vespasiano, surgen tiempos mejores para este escritor que emprende las Guerras de Germania hasta el año 37. Más tarde serán utilizadas por Tácito ${ }^{63}$. Conservamos la Naturalis Historia o investigaciones acerca del Universo, dedicadas al emperador Tito. Plinio, como ya hemos indicado, continuó la obra de Aufidio Baso, en 31 libros escritos entre el 71 y el 77 . El valor de sus obras es muy desigual. Con frecuencia se contenta con transcribir sin preocuparse de la composición. Es imitador de Séneca y abarca todos los temas como Catón y Varrón.

La biografia durante este período está representada por Marco Aquilio Régulo $^{64}$, calificado como uir malus dicendi, que informa ampliamente del período neroniano y escribe un libelo satirizando a Junio Aruleno Rústico; éste fue pretor en el 69 y autor de una Vita sobre Peto Trásea que le costó la muerte en tiempos de Domiciano ${ }^{65}$.

Un Panegírico sobre el yerno de Trásea, Helvidio el Antiguo, bien documentado gracias a su esposa Fannia, fue escrito por Herennio Senecio ${ }^{66}$, oriundo de la Hispania Bética. Un senadoconsulto ordenó la supresión de su obra y le condenó a muerte en tiempos de Domiciano.

De esta época son Tiberio Claudio Polión ${ }^{67}$, que alaba las hazañas de Lucio Annio Baso, oficial de Vespasiano y Gneo Octavio Titinio Capito, procurador ab epistulis en tiempos de Domiciano, Nerva y Trajano; amigo de Plinio el Joven ${ }^{68}$ y admirador de Bruto, Casio y Catón.

39 TÁC. Ann. 1, 69.

so SCHOL. IVV. 2, 99.

of J. WiLKeS, op. cil., pp. 199-201.

${ }^{62}$ TAC. Ann. 13, 53-57.

${ }^{63}$ TÁC. Ann. 1. 69.

64 S. GSELl, Essai sur le regne de Domitien, Paris 1894, p. 266 y G. BoISsier, L'opposition sous les Cesars, Paris 1932', pp. 193 ss.

${ }^{\circ 5}$ Dion. Cass. 67, 13.

* Plin. Ep. 7, 19,5.

(7) Cf. Plin. Ep. 7,31, 2-3.

${ }^{8}$ Plin. Ep. 8, 12, 4. 
Con Suetonio el género biográfico buscará todavía su equilibrio entre la exactitud histórica y la deformación de los libelos.

Los hombres más representativos de la época escriben sus memorias, y éste es el caso de Vespasiano, ya citado, y de Tito con sus Comentarios, obras muy analizadas posteriormente por Flavio Josefo. También dentro de este género podemos incluir a Vipstano Mesala $a^{69}$ que participó en la batalla de Cremona, del que sabemos a través de Tácito en su Dialogus de oratoribus, que fue un continuador de la oratoria clásica. Defendió a su hermanastro Aquilino Régulo ${ }^{70}$.

Dentro del período temporal que abarca nuestro trabajo, el último historiador que trataremos es el que más problemas ha suscitado con relación a su datación, pues no habla de él ningún autor de la antigüedad y sólo poseemos su obra Historia Alexandri Magni para comprobar datos sobre su vida: De esta forma la figura de Quinto Curcio es una verdadera incógnita y sus muchos investigadores no han estado de acuerdo acerca del momento en que vivió. Se han señalado las épocas de Augusto, Claudio, Nerón, Galba, Vespasiano, Septimio Severo y de Alejandro Severo. El profesor Costas $^{71}$, en el estudio más reciente de este tema, se inclina por la época de Vespasiano, alegando una serie de pruebas que nos parecen las más convincentes.

La Historia Alexandri Magni, escrita en diez libros, de los que nos faltan los dos primeros, relata, como su nombre indica, las hazañas del famoso Alejandro. Las obras de Clitarco y Calístenes son las fuentes principales de Curcio. Si bien su mayor originalidad consiste en fusionar en un conjunto coherente y claro los tratamientos contradictorios que hasta aquel momento había recibido la figura de Alejandro.

Su valor histórico ha sido muchas veces puesto en entredicho pues no sólo reproduce los errores de sus fuentes, sino que a veces introduce errores nuevos de carácter geográfico y cronológico. No considera necesario recurrir a documentos de primera mano para hacer historia de un período que otros ya han relatado. En esto se ajusta a una tradición que antes de él ya había seguido Tito Livio.

Las cualidades literarias de Quinto Curcio son menos discutidas que su valor como historiador. Está más interesado por el orden artístico que por el histórico. Tito Livio procede del mismo modo. Tácito a menudo critica esta técnica historiográfica según la cual la historia constituye un pretexto y no un fin en sí misma.

El gusto por el exotismo es un rasgo acusado en la obra de Curcio. En

69 TÁC. Hist. 3, 9, 3, 25; 3, 28.

70 TAC. Hist. 4, 40.

$"$ J. Costas Rodriguez, Aspectos del vocabulario de Curcio. Estudio semántico-lexicológico. Contribución al problema de su datación, Salamanca 1980. 
esto se separa de la mayoría de los escritores romanos que rara vez se sienten atraídos por los exótico y lo lejano.

$\mathrm{Su}$ vocabulario es ajustado y claro. No abusa del tecnicismo y utiliza pocos arcaísmos. En definitiva, es una lengua que lleva la marca de Livio y no se aleja mucho del uso clásico.

Concluimos nuestro trabajo presentando un esquema en donde hemos agrupado los representantes «menores» de la historiografia latina del siglo I, a partir de sus grandes épocas, según el estilo y concepción de la misma:

I. Epoca Julio-Claudia que recoge un género historiográfico marcado especialmente por el individualismo y un descenso en su rango, tiene sus manifestaciones en:

a) La biografia: Séneca, Julio Segundo, Asconio Pedanio, Peto Trásea y Anteyo.

b) La autobiografia: Tiberio y Claudio.

c) Las memorias: Agripina, Domicio Córbulo, Antistio Veto y Suetonio Paulino.

d) Los "Comentarios» o «Historias» de escritores políticos de carácter narrativo (Claudio, Cremucio Cordo y Lucio Getúlico), analítico (Veleyo Patérculo), retórico, moralizante y novelesco (Valerio Máximo), laudatorio (Aufidio Baso), informativo (Servilio Noniano), parcial (Cluvio Rufo) y al estilo de los libelos (Mamerco Emilio Escauro).

2. Epoca Flavia: que recoge un género historiográfico marcado por el nacionalismo y la falta de inspiración, tiene sus manifestaciones en:

a) La biografia: Marco Régulo, Tiberio Claudio Polión, Gneo Octavio Titinio Capito, Plinio el Viejo. Como un panegírico: Herencio Senecio.

b) Las memorias: Vespasiano, Tito y Vipstano Mesala.

c) Los «Comentarios»: con fines políticos (Vespasiano y Fabio Rústico), con carácter informativo (Pompeyo Planta y Plinio el Viejo). 